Pacific Journal of Mathematics

ON THE DENSITY OF CERTAIN COHESIVE BASIC 


\section{ON THE DENSITY OF CERTAIN COHESIVE BASIC SEQUENCES}

\section{Donald L. Goldsmith}

It has been shown in previous investigations of the combinatorial properties of basic sequences that any cohesive basic sequence $\mathscr{B}$ which is contained in $\mathscr{C}$ (the set of all pairs of relatively prime positive integers) must be large in some sense. To be precise, it has been proved that if $\mathscr{B}$ is a cohesive basic sequence and $\mathscr{B} \subset \mathscr{C}$, then $C_{\mathscr{B}}(p)$ is infinite for every prime $p$, where $C_{\mathscr{B}}(p)$ is the set of prime companions of $p$ in primitive pairs in $\mathscr{B}$. While this implies that $\mathscr{B}$ must contain a great many primitive pairs, no specific statement has been made about the density of $\mathscr{B}$. It is reasonable to ask, therefore, whether there are cohesive basic sequences $\mathscr{B}$, contained in $\mathscr{C}$, with density $\delta(\mathscr{B})=0$.

It is shown here that such basic sequences do exist, and a method is given for the construction of a large class of these sequences.

A proof that $C_{\mathscr{B}}(p)$ is infinite when $\mathscr{B}$ is cohesive and $\mathscr{B} \subset \mathscr{C}$ may be found in [2].

A basic sequence $\mathscr{B}$ is a set of pairs $(a, b)$ of positive integers satisfying

(i ) $(1, k) \in \mathscr{B}(k=1,2, \cdots)$,

(ii) $(a, b) \in \mathscr{B}$ if and only if $(b, a) \in \mathscr{B}$,

(iii) $(a, b c) \in \mathscr{B}$ if and only if $(a, b) \in \mathscr{B}$ and $(a, c) \in \mathscr{B}$.

A pair $(a, b)$ of positive integers is called a primitive pair if both $a$ and $b$ are primes. If $a \neq b$, the pair is a type $I$ primitive pair; if $a=b$, the pair is a type $I I$ primitive pair. If $\Phi$ is a set of pairs (primitive or not) of positive integers, the basic sequence generated by $\Phi$ is defined to be

$$
\Gamma[\Phi]=\bigcap \mathscr{D},
$$

where the intersection is taken over all basic sequences $\mathscr{D}$ which contain $\Phi$.

A basic sequence $\mathscr{B}$ is cohesive if for each positive integer $k$ there is an integer $a>1$ such that $(k, a) \in \mathscr{B}$.

Finally, we recall that the density of a basic sequence $\mathscr{B}$ is defined by

$$
\delta(\mathscr{B})=\lim _{x \rightarrow \infty} \frac{1}{N} \sum_{k=1}^{N} \frac{{ }^{\sharp} B_{k}}{d(k)}
$$


if the limit exists, where $d(k)$ is the number of positive divisors of $k$, and ${ }^{\sharp} B_{k}$ is the number of members $(m, n)$ of $\mathscr{B}$ for which $m n=k$.

2. The main theorem. We will use the following notation.

$$
P=\left\{p_{1}, p_{2}, \cdots\right\}
$$

is the sequence of all primes, written in order of increasing magnitude;

$$
Q=\left\{q_{1}, q_{2}, \cdots\right\}
$$

is any sequence of primes, also written in order of increasing size; and

$$
Q_{i}=\left\{q_{i}, q_{i+1}, q_{i+2}, \cdots\right\} \quad(i=1,2, \cdots) .
$$

We define $\mathscr{B}_{Q}$ to be the basic sequence generated by the primitive pairs

$$
\left\{\left(p_{1}, q\right) \mid q \in Q_{1}\right\} \cup\left\{\left(p_{2}, q\right) \mid q \in Q_{2}\right\} \cup \cdots
$$

REMARK 1. $\mathscr{B}_{Q}$ is cohesive. For suppose $k>1$, so that $k=$ $p_{i_{1}}^{t_{1}} p_{i_{2}}^{t_{2}} \cdots p_{i_{M}}^{t_{M}}$ where $i_{1}<i_{2}<\cdots<i_{M}$. Then $\left(q_{i_{I I}}, p_{i_{j}}\right) \in \mathscr{B}_{Q}$ for $j=$ $1,2, \cdots, M$, so $\left(q_{i_{M}}, k\right) \in \mathscr{B}_{Q}$.

REMARK 2. $\mathscr{B}_{Q} \subset \mathscr{C l}$ if $q_{1} \geqq 3$. For if $q_{1} \geqq 3\left(=p_{2}\right)$ then $q_{i}>p_{i}$ for every $i$, and $\mathscr{B}_{Q}$ will contain no type II primitive pairs.

THEOREM. If $\sum_{i=1}^{\infty} 1 / q_{i}$ converges, then $\delta\left(\mathscr{B}_{Q}\right)=0$.

Proof. Let $L$ be a (large) fixed, but arbitrary positive integer which will be determined later. Decompose the set $\boldsymbol{Z}^{+}$of positive integers as follows:

(a) $X^{\prime}=\left\{k \mid{ }^{\sharp} B_{k}=2\right\}$,

(b) $X^{\prime \prime}=\left\{k \mid k \notin X^{\prime}\right.$ and $k$ has less than $4 L$ different prime divisors $\}$,

(c) $Y=\left\{k \mid k \notin\left(X \cup X^{\prime \prime}\right)\right\}$.

In order to prove that $\delta\left(\mathscr{B}_{Q}\right)=0$, let us consider

$$
\frac{1}{N} \sum_{\substack{k=1 \\ k \in S}}^{N} \frac{\# B_{k}}{d(k)},
$$

where $S=X^{\prime}, X^{\prime \prime}$ and $Y$.

By Lemma 3.2 in [1], we have

$$
\lim _{N \rightarrow \infty} \frac{1}{N} \sum_{\substack{k=1 \\ k \in X^{\prime}}}^{N} \frac{\# B_{k}}{d(k)} \leqq \lim _{N \rightarrow \infty} \frac{1}{N} \sum_{k=1}^{N} \frac{2}{d(k)}=0,
$$


while by Theorem 11.8 in [3] we have

$$
\lim _{N \rightarrow \infty} \frac{1}{N} \sum_{\substack{k=1 \\ k \in X^{\prime \prime}}}^{N} \frac{{ }^{\prime \prime} B_{k}}{d(k)} \leqq \lim _{N \rightarrow \infty} \frac{1}{N} \sum_{\substack{k=1 \\ k \in X^{\prime \prime}}}^{N} 1=0 .
$$

It remains to estimate the sum in (2.1) when $S=Y$. Since

$$
\frac{1}{N} \sum_{\substack{k=1 \\ k \in Y}}^{N} \frac{\sharp B_{k}}{d(k)} \leqq \frac{1}{N} \sum_{\substack{k=1 \\ k \in Y}}^{N} 1
$$

we will find an upper bound for the number of elements of $Y$ which do not exceed $N$. Our estimate will depend on the following

Lemma. Every integer in $Y$ is divisible by at least one of the primes $q_{i}$ with $i \geqq L$.

Proof of the Lemma. Let $k$ be an element of $Y$. Then ${ }^{\ddagger} B_{k}>2$, so there are integers $u, v$ such that

$$
k=u v, u>1, v>1,(u, v) \in \mathscr{B}_{Q} .
$$

Suppose that $u$ and $v$ are expressed canonically as products of prime powers:

$$
u=p_{i_{1}}^{a_{1}} p_{i_{2}}^{a_{2}} \cdots p_{i_{r}}^{a_{r}}, \quad v=p_{j_{1}}^{b_{1}} p_{j_{2}}^{b_{2}} \cdots p_{j_{s}}^{b_{s}},
$$

where $r \geqq 1, s \geqq 1, p_{i_{1}}<p_{i_{2}}<\cdots<p_{i_{r}}, p_{j_{1}}<p_{j_{2}}<\cdots<p_{j_{s}}$. Since $k$ is divisible by at least $4 L$ distinct primes, we have $r+s \geqq 4 L$. At least one of the numbers $r, s$ must be $\geqq 2 L$, say

$$
r \geqq 2 L \text {. }
$$

If $p_{j_{1}} \in Q$, then every prime divisor of $u$ is in $Q$ since every primitive pair in $\mathscr{B}_{Q}$ contains at least one member from $Q$. Hence $p_{i_{r}}=q_{i}$ (for some $q_{i}$ in $Q$ ) and $q_{i} \geqq q_{r} \geqq q_{2 L}$.

Suppose, on the other hand, that $p_{j_{1}}$ is in $Q$. Now separate the primes $p_{i_{1}}, \cdots, p_{i_{r}}$ into two classes, depending on whether or not they are in $Q$. Let $x_{1}, \cdots, x_{2}$, be those not in $Q$, written in order of ascending size, and let $y_{1}, \cdots, y_{\nu}$ be those in $Q$, also given in ascending order. Thus

$$
u=x_{1}^{c_{1}} \cdots x_{\lambda}^{c_{\lambda} \lambda} y_{1}^{d_{1}} \cdots y_{\nu}^{d_{\nu}}
$$

with

$$
\lambda+\nu=r \geqq 2 L .
$$

It follows from (2.5) that either $\lambda \geqq L$ or $\nu \geqq L$.

If $\lambda \geqq L$, then $x_{\lambda}=p_{m}$ for some $m \geqq L$. Since $p_{m} \notin Q$, only 
the primes in $Q_{m}$ appear as companions of $p_{m}$ in primitive pairs of $\mathscr{B}_{Q}$. In particular, since $\left(p_{m}, p_{j_{1}}\right) \in \mathscr{B}_{Q}$, we have

$$
p_{j_{1}} \in Q_{m} \subset Q_{L} \text {. }
$$

Thus $p_{j_{1}} \in Q, p_{j_{1}} \geqq q_{L}$, and $p_{j_{1}} \mid k$.

If $\nu \geqq L$, then $y_{\nu} \in Q, y_{\nu} \geqq q_{L}$, and $y_{\nu} \mid k$.

That proves the Lemma.

We return to the estimation of the second sum in (2.4). As a consequence of the Lemma we have

$$
\begin{aligned}
\sum_{\substack{k=1 \\
k \in Y}}^{N} 1 & \leqq \sum_{\substack{k=1 \\
l i \mid}}^{N} 1 \\
& \leqq \sum_{i=L}^{\infty}\left[\frac{N}{q_{i}}\right] \\
& \leqq N \sum_{i=L}^{\infty} \frac{1}{q_{i}},
\end{aligned}
$$

and this together with (2.4) gives

$$
\frac{1}{N} \sum_{\substack{k=1 \\ k \in Y}}^{N} \frac{\sharp B_{k}}{d(k)} \leqq \sum_{i=L}^{\infty} \frac{1}{q_{i}} .
$$

Now let $\varepsilon>0$ be given and choose $L$ large enough so that

$$
\sum_{i=L}^{\infty} \frac{1}{q_{i}}<\frac{\varepsilon}{3}
$$

( $L$ depends only on $\varepsilon$ and $Q$ ). Then from (2.6) we have

$$
\frac{1}{N} \sum_{\substack{k=1 \\ k \in Y}}^{N} \frac{{ }^{*} B_{k}}{d(k)}<\frac{\varepsilon}{3},
$$

and it follows from (2.2), (2.3) and (2.7) that there is an integer $N_{0}(\varepsilon)$ such that

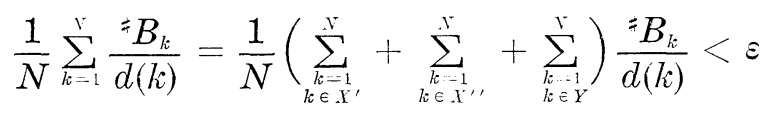

when $N \geqq N_{0}(\varepsilon)$.

That proves $\delta\left(\mathscr{B}_{\ell}\right)=0$, and completes the proof of the Theorem.

By Remarks 1 and 2 and the Theorem, each sequence $Q$ of distinct odd primes such that $\Sigma 1 / q_{j}$ converges leads to a cohesive basic sequence. $\mathscr{B}_{Q}$ in . $\mathscr{l}$ such that $\delta\left(. D_{Q}\right)=0$. 


\section{REFERENCES}

1. D. L. Goldsmith, On the multiplicative properties of arithmetic functions, Pacific J. Math., 27 (1968), 283-304.

2. D. L. Goldsmith and A. A. Gioia, Convolutions of arithmetic functions over cohesive basic sequences, Pacific J. Math., 38 (1971), 391-399.

3. I. Niven and H. S. Zuckerman, An Introduction to the Theory of Numbers, Second Edition, Wiley, New York, 1960.

Received April 19, 1971. This reseach was supported in part by Western Michigan University under a Faculty Research Fellowship.

Western Michigan University 



\section{PACIFIC JOURNAL OF MATHEMATICS}

\section{EDITORS}

\author{
H. SAMELSON \\ Stanford University \\ Stanford, California 94305 \\ C. R. HOBBY \\ University of Washington \\ Seattle, Washington 98105
}

\section{J. DuGundJI}

Department of Mathematics University of Southern California Los Angeles, California 90007

RICHARD ARENS

University of California

Los Angeles, California 90024

\section{ASSOCIATE EDITORS}
E. F. BECKENBACH
B. H. NeumanN
F. WOLF
K. YOSHIDA

\section{SUPPORTING INSTITUTIONS}

\author{
UNIVERSITY OF BRITISH COLUMBIA \\ CALIFORNIA INSTITUTE OF TECHNOLOGY \\ UNIVERSITY OF CALIFORNIA \\ MONTANA STATE UNIVERSITY \\ UNIVERSITY OF NEVADA \\ NEW MEXICO STATE UNIVERSITY \\ OREGON STATE UNIVERSITY \\ UNIVERSITY OF OREGON \\ OSAKA UNIVERSITY
}

\author{
UNIVERSITY OF SOUTHERN CALIFORNIA \\ STANFORD UNIVERSITY \\ UNIVERSITY OF TOKYO \\ UNIVERSITY OF UTAH \\ WASHINGTON STATE UNIVERSITY \\ UNIVERSITY OF WASHINGTON \\ AMERICAN MATHEMATICAL SOCIETY \\ NAVAL WEAPONS CENTER
}

The Supporting Institutions listed above contribute to the cost of publication of this Journal, but they are not owners or publishers and have no responsibility for its content or policies.

Mathematical papers intended for publication in the Pacific Journal of Mathematics should be in typed form or offset-reproduced, (not dittoed), double spaced with large margins. Underline Greek letters in red, German in green, and script in blue. The first paragraph or two must be capable of being used separately as a synopsis of the entire paper. The editorial "we" must not be used in the synopsis, and items of the bibliography should not be cited there unless absolutely necessary, in which case they must be identified by author and Journal, rather than by item number. Manuscripts, in duplicate if possible, may be sent to any one of the four editors. Please classify according to the scheme of Math. Rev. Index to Vol. 39. All other communications to the editors should be addressed to the managing editor, Richard Arens, University of California, Los Angeles, California, 90024.

50 reprints are provided free for each article; additional copies may be obtained at cost in multiples of 50 .

The Pacific Journal of Mathematics is published monthly. Effective with Volume 16 the price per volume (3 numbers) is $\$ 8.00$; single issues, $\$ 3.00$. Special price for current issues to individual faculty members of supporting institutions and to individual members of the American Mathematical Society: $\$ 4.00$ per volume; single issues $\$ 1.50$. Back numbers are available.

Subscriptions, orders for back numbers, and changes of address should be sent to Pacific Journal of Mathematics, 103 Highland Boulevard, Berkeley, California, 94708.

PUBLISHED BY PACIFIC JOURNAL OF MATHEMATICS, A NON-PROFIT CORPORATION

Printed at Kokusai Bunken Insatsusha (International Academic Printing Co., Ltd.), 270, 3-chome Totsuka-cho, Shinjuku-ku, Tokyo 160, Japan. 


\section{Pacific Journal of Mathematics}

\section{Vol. 42, No. $2 \quad$ February, 1972}

Stephen Richard Bernfeld, The extendability of solutions of perturbed scalar differential equations ................................. 277

James Edwin Brink, Inequalities involving $f_{-} p$ and $f^{(n)}{ }_{q}$ for $f$ with $n$

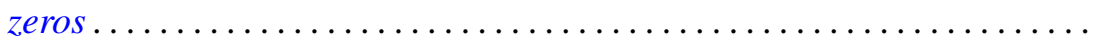

Orrin Frink and Robert S. Smith, On the distributivity of the lattice of filters of a groupoid

Donald Goldsmith, On the density of certain cohesive basic sequences .... 323

Charles Lemuel Hagopian, Planar images of decomposable continua . . . . . 329

W. N. Hudson, A decomposition theorem for biadditive processes ........ 333

W. N. Hudson, Continuity of sample functions of biadditive processes......

Masako Izumi and Shin-ichi Izumi, Integrability of trigonometric series.

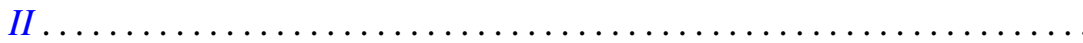

H. M. Ko, Fixed point theorems for point-to-set mappings and the set of

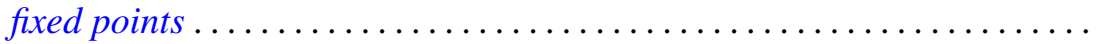

Gregers Louis Krabbe, An algebra of generalized functions on an open interval: two-sided operational calculus ...

Thomas Latimer Kriete, III, Complete non-selfadjointness of almost selfadjoint operators.................................

Shiva Narain Lal and Siya Ram, On the absolute Hausdorff summability of a Fourier series .

Ronald Leslie Lipsman, Representation theory of almost connected groups...

James R. McLaughlin, Integrated orthonormal series.... . .

H. Minc, On permanents of circulants.

Akihiro Okuyama, On a generalization of $\Sigma$-spaces.....

Norberto Salinas, Invariant subspaces and operators of class $(S)$

James D. Stafney, The spectrum of certain lower triangular matrices as operators on the $l_{p}$ spaces .......................

Arne Stray, Interpolation by analytic functions

$\mathrm{Li} \mathrm{Pi} \mathrm{Su}$, Rings of analytic functions on any subset of the complex plane.

R. J. Tondra, A property of manifolds compactly equivalent to compact manifolds.... 